\title{
Assessment of Knowledge, Attitude and Practice (KAP) on Prevention of Malaria at Gode Lalo Kebele (010), Anchar Woreda, West Haraarge Zone, Oromia, Ethiopia: A Community Based Descriptive Cross-Sec- tional Study Methods
}

\author{
Rahel Miliyon Mokonen, BSc ${ }^{1^{*}}$, Maleda Tefera Iffa, BSc, MSc ${ }^{2}$ and Masresha Leta Serbesa, BSc, MSc ${ }^{3}$ \\ ${ }^{1}$ Department of nursing, Harar Health Science College, Harar, Ethiopia \\ ${ }^{2}$ Department of Nursing and Midwifwery, Haramaya University, Harar, Ethiopia \\ ${ }^{3}$ Department of Midwifery, Harar Health Science College, Harar, Ethiopia

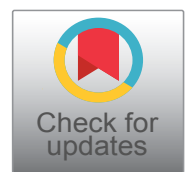

*Corresponding author: Rahel Miliyon Mokonen, Department of nursing, Harar Health Science College, Harar, Ethiopia

\begin{abstract}
Introduction: Malaria is a major public health problem in worldwide and causes high morbidity and mortality, despite global efforts to eradicate the disease. While the disease is easily preventable, curable and treatable, it remains a big health threat to many communities all over the world; most especially in Sub-Saharan Africa. Malaria affects about $5 \%$ the world's population. It is the leading cause of death in children under 5 years in sub Saharan Africa still among the ten top leading causes of morbidity and mortality. Thus, one child dies of malaria in Africa every 30 seconds, which translates into a tragic 3000 children each day. Approximately 57.3 million (68\%) of the 84.3 million population of Ethiopia live in areas at risk of malaria. According to the $\mathrm{FMOH}$, malaria was the leading cause of outpatient visits and health facility admissions in 2010/2011, accounting for $15 \%$ of reported outpatient visits and nearly $15 \%$ of admissions.
\end{abstract}

Objective: The main objective of this study was to assess the level of knowledge, attitude and practices of Gode lalo Kebele (010) community towards malaria prevention and control in Anchar Woreda.

Methods: A community based descriptive Cross-sectional study was conducted in Gode lalo Kebele (010) Anchar Woreda, from February-June 2018. A systemic random sampling technique was used to select 271 samples from general populations. A structured questionnaire was used as a tool for data collection and data was collected by volunteer health extension workers and finally data was processed and analyzed manually/Electronically compilation.
Results: Most of the respondents demonstrated some understanding of malaria, its transmission and prevention methods, and the attitude of large majority of the respondents towards malaria prevention methods was positive, but majority of the respondents practiced them occasionally and there was association between some demographic Characteristics and communities' practice of malaria prevention methods. Lack of accessibility and knowledge about where about of methods, their expensiveness makes their practicality beyond individual effort and demanded community effort.

Conclusions and recommendations: The study community had good knowledge on both malaria and its control interventions and have positive attitude towards malaria prevention methods. And most of them practiced malaria prevention methods occasionally, therefore it is recommended that Health sector officials should; increase accessibility, provide them at affordable price, increase community awareness about their availability, Study results also indicated that there was association between some demographic characteristics and communities practice of malaria prevention methods and further study is recommended to explore if there is causal relationship between demographic characteristics and communities practice of malaria prevention methods.

\section{Keywords}

Knowledge, Attitude, Practice, Malaria, Godelalo kebele (010) 


\section{List of Acronyms and Abbreviation}

ANC: Antenatal Care, CHW: Community Health Worker, BCC: Behavior Change Communication; DC: Data Collector; EC: Ethiopian Calendar; FMOH: Federal Ministry of Health; FGD: Focus Group Discussion; ITN: Insecticide Treated Nets; KAP: Knowledge, Attitudes and Practices; MCP: Malaria Control Programmers; PI: Principal Investigator; RBM: Roll Back Malaria; SPSS: Statically Program for Social Science; VHT: Village Health Team; WHO: World Health Organization

\section{Background}

Despite being preventable and treatable, malaria continues to have a devastating impact on people's health and livelihoods around the world. According to the latest available data, about 3.2 billion people were at risk of the disease in 106 countries, territories and areas in 2015, and an estimated 214 million cases occurred (range: 149-303 million). In the same year, the disease killed about 438000 people (range: 236000635000) from this 306000 children aged under 5 years in globally with the bulk of this in sub-Saharan Africa. In most countries where malaria is endemic, the disease disproportionately affects poor and disadvantaged people, who have limited access to health facilities and can barely afford the recommended treatment. Between 2000 and 2015, a substantial expansion of malaria interventions contributed to a $48 \%$ decline in malaria mortality rates globally, averting an estimated 4.38 million deaths. In the WHO African Region, the malaria mortality rate in children under 5 years of age was reduced by $60 \%$. During the same period, the global incidence of malaria was reduced by $37 \%[1,2]$.

Malaria is seasonal in most parts of Ethiopia, with unstable transmission that lends itself to the outbreak of epidemics. The transmission patterns and intensity vary greatly due to the large diversity in altitude, rainfall, and population movement [3]. Areas lying below 2000 meter altitude are malarias. Those areas are home to approximately $68 \%$ of the Ethiopian population and cover almost $75 \%$ of the country's landmass [4].

In 2010, the Federal Ministry of Health (FMOH) reported 4,068,764 clinical and confirmed malaria cases to the World Health Organization (WHO) as recorded in the 2011 World Malaria Report [5]. Malaria is ranked as the leading communicable disease in Ethiopia, accounting for about $30 \%$ of the overall Disability Adjusted Life Years lost. Approximately 57.3 million (68\%) of the 84.3 million population of Ethiopia live in areas at risk of malaria. According to the $\mathrm{FMOH}$, malaria was the leading cause of outpatient visits and health facility admissions in 2010/2011, accounting for $15 \%$ of reported outpatient visits and nearly $15 \%$ of admissions. Malaria also was among the ten leading causes of inpatient deaths among children less than five years of age [6].
Early detection and prompt treatment of malaria cases, selective vector control (indoor residual spray, use of insecticide treated mosquito nets and source reduction) and epidemic prevention and control are the major strategies adopted in the country. So far, the application of in-house insecticide spraying has been at the center of vector control operations. Currently, insecticide treated mosquito nets (ITNs) have received serious attention and have raised renewed interest to serve as tools in malaria control [7].

Even though malaria continues to have a devastating impact on people's health and livelihoods Around the world, between 2000 and 2015, a substantial expansion of malaria interventions Contributed to a $48 \%$ decline in malaria mortality rates globally, averting an estimated 4.38 Million deaths. In the WHO African Region, the malaria mortality rate in children under 5 Years of age was reduced by $60 \%$. Despite this progress, the disease remains endemic in all six WHO regions and the burden is heaviest in the African Region, where an estimated $88 \%$ of all Malaria deaths occur. Around the world, millions of people remain without access to malaria Prevention and treatment, and most cases and deaths go unregistered and unreported. Given the Projected growth in the size of the world's population by 2030 , more people will be living in Countries where malaria is a risk, putting further strains on health systems and national malaria Programmers budgets [1].

According to world malaria report of 2015, the incidence rate of malaria is estimated to have Decreased by $37 \%$ globally between 2000 and 2015 . Decreases in incidence rates have been Greatest in the WHO European Region (100\%) and the WHO South-East Asia Region (54\%). However, progress has been slow in the WHO African Region, which is the region that carries The heaviest malaria burden [6]. According to the $\mathrm{FMOH}$, malaria was the leading cause of outpatient visits and health facility admissions in 2010/2011, accounting for $15 \%$ of reported outpatient visits and nearly $15 \%$ of admissions.

Malaria is ranked as the leading communicable disease in Ethiopia, accounting for about $30 \%$ of the overall Disability Adjusted Life Years lost. Approximately 57.3 million (68\%) of the 84.3 million population of Ethiopia live in areas at risk of malaria. According to the $\mathrm{FMOH}$, malaria was the leading cause of outpatient visits and health facility admissions in 2010/2011, accounting for $15 \%$ of reported outpatient visits and nearly $15 \%$ of admissions. Malaria also was among the ten leading causes of inpatient deaths among children less than five years of age [8].

In Oromia regional health bureau report, in 2008 and 2009 malaria accounted for 248651/193274 of outpatient visits, 5658/3804 of hospital admissions and 54/55 of deaths respectively in oromia. In Anchar woreda of Ethiopia, in 2009 malaria accounted for 14\% of outpatient visits, $5 \%$ of hospital admissions and $2 \%$ 
of deaths [9].

Transmission of malaria in Ethiopia is closely linked with the rainy seasons, i.e. the summer and winter rains. The major transmission seasons follow the JuneSeptember rains and occurs between April to-May following the February to March winter rains.

The minor transmission is limited to a few areas that receive the Winter rains while the major transmission season occurs almost in every part of the country [10].

The increasing trend in malaria transmission over the last few years is also believed to have been aggravated by the unstable weather conditions, the over increasing population movement to and from malarias areas and the declining efficacy of anti-malarial mono therapies [3].

Thus, WHO has been playing a leading role in the adoption and implementation of malaria prevention and control activities that are technically sound and suited to the malaria epidemic Efforts to ensure access to early diagnoses and prompt treatment with safe and effective drugs, timing and targeting of selective vector control with emphasis on the use of insecticide treated nets and indoor residual spraying and strengthening the capacity in epidemic monitoring preparedness and response have been due attention [3].

According to information obtained from the head of communicable disease control department of Anchar wereda Health Office, malaria is one of the leading causes of morbidity and Gode lalo kebele (010) is also among the malarious 's kebeles in the Woreda but till now no study was carried out on this kebele concerning Knowledge and Practice of Malaria prevention [8].

Taking this situation in to consideration, this research aims at conducting study to identify the knowledge attitude and practice to-wards malaria prevention of Gode lalo kebele (010), Anchar woreda. Therefore, this study would serve as a reference material for both academicians and practitioners, provide information about KAP of malaria prevention of Godelalo kebele (010), community for health workers, supportive staff members and Keble health post in order to develop action plan to strengthen the community awareness, initiate policy makers to craft appropriate policy to enhance KAP of the community and, It will also initiate other interested researchers to carry out more extensive studies in the area.

\section{Method and Material}

A community based cross sectional study design was employed from January-June 2018 among 271 randomly selected households at west Hararge Zone, Anchar Woreda, Gode lalo Kebele (010). The study was carried out in west Hararge Zone, Anchar Woreda, Gode lalo Kebele (010). It is located in Eastern part of Oromia, $325 \mathrm{~km}$ from Addis Ababa to East and $131 \mathrm{~km}$ from ciro town to west. Its climatic condition is "kola" (temperate zone).

The woreda has 28 kebeles as a whole. According to survey conducted in 2009 the projected total population of this woreda is 116391 . Males to females' ratio are 1:1. From this, Gode lalo Kebele (010) has a total population of 5376 and about 1140 households divided in to three Villages. The economic base of the woreda is mainly depends on agriculture $\&$ trading. In the woreda there are 5 governmental Health Centers, 28 Health Posts and 7 private small clinics. They are giving promotion, prevention and curative health services for the community.

Sample size was determined by using a single proportion sample size calculation formula with a source of population size greater than 10,000 . Assuming the prevalence of the national prevalence of General malaria knowledge and good practices (KAP) at $71.5 \%$ derived from the Ethiopia National Malaria Indicator Survey 2011 Technical Summary [11], and margin of Error 5\% and $95 \%$ confidence interval and adding non-responses rate of $10 \%$. Since our source population was less than 10,000 , finite population correction was made. Accordingly, the sample size of 271 was obtained. So data were collected using Systematic sampling technique. Among members of the gode Lalo kebele (010) Community sample interviewee was selected randomly. The total number of households of the Kebele is 1140 . Then after using a lottery methods selection of the first household the Next every other $\mathrm{K}^{\text {th }}=1140 / 271=4$ households were included in the study until calculated sample size reached.

Data was collected by interviewing either head of the households, their spouses or other member of households whose age is above 18 and available at home at the time of survey using structured questioner which were prepared in English that was translated to Oromifa by linguistic professionals. That was translated back to English for its consistency and to made it simple during administration. Matching was made on the exact fitness of the two languages. The data was collected with a face-to-face interview by using open and close ended equations. The quality of data was assured by training of data collectors and supervisors, properly designing and pre-testing of the questionnaire. Four diploma Midwifery holder individuals were involved for data collection and three days training was given for the data collectors and supervisors before the actual work began about the data collection procedures, proper categorization and coding of the questionnaire. A pretest was conducted in five percent of the total sample size on population outside of the study area. The pretest as well as the study was done by trained data collectors and any ambiguous and unclear questions were be modified after the pretest was conducted. After checking of questioner completeness with pretest, the actual data collection was conducted by using structure 
questionnaire. 3 data collectors who were diploma nurses and 2 supervisors of BSC nurse holder and experienced in previous data collection and supervision activities were involved.

After data collection, each questionnaire was checked for completeness, then coded and entered into Microsoft excel program for cleaning, editing, and analysis. The results was presented in the form of tables, figures and text using frequencies and summary statistics such as mean, mode, standard deviation and percentage to describe the study population in relation to relevant variables.

In order to confirm the ethical and legal standard of the investigator, approval was obtained from the ethical review board of Haramaya university College of Health and medical Science. The survey was commence after written consent obtained from the woreda health office.

\section{Result}

\section{Socio-demographic and economic characteristics}

A total of 271 questionnaires were filled by interviewing the respondents, and the response rate of $100 \%$ was achieved. With the help of Microsoft Excel analysis tool, Descriptive statistics were used to present and analyze the data. Demographic Profile of Respondents by Gender Distribution There were 178 male (65.7\%) and 71 female 93 (34.3\%) customers participating in this study (Table 1 ).

Most of the respondents were of age group 20-30 (50.2\%), 27.3\% were between age group 31-40, 9.2\% were above 50 years $7.4 \%$ were between age group 41 50 and $5.9 \%$ were between age group $<20$-years-old (Table 2).

The occupations of large majority of the respondents (64.9\%) were Farmers, while the $28.8 \%$ were House

Table 1: Socio-demographic characteristics of respondents at Gode lalo kebele on KAP toward malaria prevention 2018 $(n=271)$.

\begin{tabular}{|l|l|l|}
\hline Sex of the respondent & Frequency & Percent \\
\hline male & 178 & 65.7 \\
\hline Female & 93 & 34.3 \\
\hline Total & 271 & 100 \\
\hline
\end{tabular}

Table 2: Age distribution of respondents at Gode lalo kebele on KAP toward malaria prevention $2018(n=271)$.

\begin{tabular}{|l|l|l|}
\hline Age of the respondent & Frequency & Percent \\
\hline$<20$ years & 16 & 5.9 \\
\hline $20-30$ years & 136 & 50.2 \\
\hline $31-40$ years & 74 & 27.3 \\
\hline $41-50$ years & 20 & 7.4 \\
\hline > 50 years & 25 & 9.2 \\
\hline Total & 271 & 100 \\
\hline
\end{tabular}

wife, $5.9 \%$ were merchant and $0.4 \%$ of the respondents were Governmental Employer (Table 3).

\section{Respondents' general awareness about malaria}

All the respondents had heard and know about malaria in general. The awareness of respondents about malaria in general is tabulated.

\section{Respondents' awareness about the mode of transmission of malaria}

Among 271 respondents $76.8 \%$ (208) of them knew the mode of transmission for malaria. While $23.2 \%$ (63) of the respondents did not know the mode of transmission for malaria. The Awareness of respondents about the mode of transmission of malaria (Table 4).

\section{Respondents' awareness about the preventability of malaria}

Among 271 respondents $98.5 \%$ (267) of them knew that malaria is a preventable disease while for $1.5 \%$ (4) of the respondents malaria is not a preventable disease. The awareness of respondents about the preventability of malaria is tabulated in (Table 5).

\section{Knowledge of malaria prevention methods}

The Knowledge of Malaria Prevention Methods of large majority of the respondents (83\%) was good,

Table 3: Occupational status of respondents at Gode lalo kebele on KAP toward malaria prevention $2018(n=271)$.

\begin{tabular}{|l|l|l|}
\hline $\begin{array}{l}\text { Occupational status of the } \\
\text { respondent }\end{array}$ & Frequency & Percent \\
\hline Governmental Employer & 1 & 0.4 \\
\hline Farmer & 176 & 64.9 \\
\hline Merchant & 16 & 5.9 \\
\hline Daily laborers & 0 & 0 \\
\hline House wife & 78 & 28.8 \\
\hline Jobless & 0 & 0 \\
\hline Others & 0 & 0 \\
\hline Total & 271 & 100 \\
\hline
\end{tabular}

Table 4: Knowledge of respondents towards person to person transmission of malaria at Gode lalo kebele, $2018(n=271)$.

\begin{tabular}{|l|l|l|}
\hline $\begin{array}{l}\text { Can malaria be transmitted } \\
\text { from person to person? }\end{array}$ & Frequency & Percent \\
\hline Yes & 208 & 76.8 \\
\hline No & 63 & 23.2 \\
\hline Total & 271 & 271 \\
\hline
\end{tabular}

Table 5: Respondents' awareness about the preventability of malaria, at Gode lalo kebele, $2018(n=271)$.

\begin{tabular}{|l|l|l|}
\hline Is malaria preventable disease? & Frequency & Percent \\
\hline Yes & 267 & 98.5 \\
\hline No & 4 & 1.5 \\
\hline Total & 271 & 271 \\
\hline
\end{tabular}


while $10 \%$ had satisfactory knowledge and $7 \%$ of the respondents had poor knowledge of Malaria protection methods (Table 6).

\section{Attitude towards malaria prevention methods}

The Attitude towards Malaria Prevention Methods of large majority of the respondents (87.8\%) was positive, while $12.2 \%$ of the respondents had negative attitudes towards Malaria protection methods. The Attitude

Table 6: Respondents' Knowledge of Malaria Prevention Methods, at Gode lalo kebele, $2018(n=271)$.

\begin{tabular}{|l|l|l|}
\hline Malaria Prevention Methods & Frequency & Percent \\
\hline Good & 225 & 83 \\
\hline Satisfactory & 27 & 10 \\
\hline Poor & 19 & 7 \\
\hline Total & 271 & 100 \\
\hline
\end{tabular}

Table 7: Respondents' Attitude towards Malaria Prevention Methods, at Gode lalo kebele, $2018(n=271)$.

\begin{tabular}{|l|l|l|}
\hline Malaria Prevention Methods & Frequency & Percent \\
\hline Agree & 96 & 35.4 \\
\hline Strongly agrees & 142 & 52.4 \\
\hline Disagree & 23 & 8.5 \\
\hline Strongly disagree & 10 & 3.7 \\
\hline Total & 271 & 100 \\
\hline
\end{tabular}

Table 8: Respondents' Practices of Malaria Prevention Methods, at Gode lalo kebele, $2018(n=271)$.

\begin{tabular}{|l|l|l|}
\hline Malaria Prevention Methods & Frequency & Percent \\
\hline Every time & 139 & 51.3 \\
\hline Sometime & 83 & 30.6 \\
\hline Never & 49 & 18.1 \\
\hline Total & 271 & 100 \\
\hline
\end{tabular}

towards Malaria protection methods of respondents is tabulated and presented graphically in (Table 7).

\section{Practices of malaria prevention methods}

The practice of Malaria Prevention Methods of Large majority of the respondents (51.3\%) practice of Malaria Prevention methods every time while $30.6 \%$ of the respondents sometime practice Malaria prevention methods and $18.1 \%$ of the respondents had never practiced Malaria prevention methods (Table 8).

\section{Gender and practices of malaria prevention meth- ods}

The association between respondents Gender and their practice of malaria prevention methods are presented below.

According to the Table 9 among respondents with Gender and Practices status who are male 71 (26.2\%) and Female $68(25 \%)$ respectively practice malaria prevention methods every time.

According to the Table 9 among respondents with Gender and Practices status who are male 65 (24\%) and Female 18 (6.6\%) respectively practice malaria prevention methods sometime.

According to the Table 9 below among respondents with Gender and Practices status who are male 42 (15.5\%) and Female 7 (2.6\%) respectively practice malaria prevention methods never (Table 9).

\section{Age in Years and practices of malaria prevention methods cross tabulation}

The association between respondents Age and their practice of malaria prevention methods are presented below.

Table 9: Relation of Respondents' gender with their practices level toward of malaria prevention methods, at Gode lalo kebele, $2018(n=271)$.

\begin{tabular}{|l|l|l|l|l|}
\hline \multirow{2}{*}{} & \multicolumn{4}{|l|}{ Gender and Practices of using Malaria Prevention Methods } \\
\hline & Every time & Sometime & Never & Total \\
\hline Female & 71 & 65 & 42 & 178 \\
\hline Total & 68 & 18 & 7 & 93 \\
\hline
\end{tabular}

Table 10: Relation of Respondents' age with their Practices level toward malaria prevention methods, at Gode lalo kebele, 2018 $(n=271)$.

\begin{tabular}{|l|l|l|l|l|}
\hline Age in Years & \multicolumn{4}{l|}{ Respondents practices of malaria prevention methods } \\
\hline & Every time & Sometime & Never & Total \\
\hline $18-20$ years & 9 & 4 & 3 & 16 \\
\hline $20-30$ years & 83 & 35 & 18 & 136 \\
\hline $31-40$ years & 29 & 29 & 16 & 74 \\
\hline $41-50$ years & 7 & 7 & 6 & 20 \\
\hline$>50$ years & 11 & 8 & 6 & 25 \\
\hline Total & 139 & 83 & 49 & 271 \\
\hline
\end{tabular}


According to the Table 10 among respondents with age in years status who are $18-20$ years, $20-30$ years, $31-40$ years, 41-50 years and above 50 years 9 (3.3\%), $83(30.6 \%), 29(10.7 \%), 7(2.6 \%), 11(4 \%)$ respectively practice malaria prevention methods every time.

According to the Table 10 among respondents with age in years status who are $18-20$ years, $20-30$ years, $31-40$ years, $41-50$ years and above 50 years $4(1.5 \%)$, 35 (12.9\%), 29 (10.7\%), 7 (2.6\%), 8 (3\%) respectively practice malaria prevention methods Sometime.

According to the table below among respondents with age in years status who are 18-20 years, 20-30 years, 31-40 years, $41-50$ years and above 50 years $3(1.1 \%), 18$ (6.6\%), 16 (5.9\%), 6 (2.2\%), 6 (2.2\%) respectively practice malaria prevention methods never (Table 10) .

\section{Education and practices of malaria prevention methods distribution}

The association between respondents Education and their practice of malaria prevention methods are presented below.

According to the Table 11 among respondents with Education status who are illiterates, only reading and writing, grade $1-8$, grade $9-12$ and above grade 12,123 $(45.4 \%), 8(3 \%), 4(1.5 \%), 3(1.1 \%), 1(0.4 \%)$ respectively practice malaria prevention methods every time.

According to the Table 11 among respondents with Education status who are illiterates, only reading and writing, grade 1-8, grade 9-12 and above grade 12,55 (20.3\%), 16 (5.9\%), 12 (4.4\%), 0 (0\%), 0 (0\%) respectively practice malaria prevention methods sometime.
According to the Table 11 among respondents with Education status who are illiterates, only reading and writing, grade 1-8, grade $9-12$ and above grade 12,36 $(13.3 \%), 5(1.9 \%), 7(2.6 \%), 1(0.4 \%), 0(0 \%)$ respectively practice malaria prevention methods never (Table 11).

\section{Occupational status and practices of malaria pre- vention methods}

The association between respondents Occupational status and their practice of malaria prevention methods are presented below.

According to the Table 12 among respondents with Occupational status who are Governmental Employer, Farmer, merchant and House wife, 1 (0.4\%), 107 $(39.5 \%), 8(3 \%)$ and $23(8.5 \%)$ respectively were practice malaria prevention methods every time.

According to the Table 12 among respondents with Occupational status who are Farmer, merchant and Daily laborers 36 (13.3\%), 5 (1.9\%) and 42 (15.5\%) respectively were practice malaria prevention methods sometime.

According to the Table 12 among respondents with Occupational status who are Farmer, merchant an Daily laborers, respectively were practice malaria prevention methods never (Table 12).

\section{Reasons for not using malaria prevention methods}

The Reasons for not using Malaria prevention methods for large majority of the respondents $(29.9 \%)$ was lack of accessibility, for $11.1 \%$ of the respondents the methods were expensive, $4.7 \%$ of the respondents didn't know where the methods were available, $2 \%$

Table 11: Relation of Respondents' educational status with their Practices level toward of malaria prevention methods, at Gode lalo kebele, $2018(n=271)$.

\begin{tabular}{|l|l|l|l|l|}
\hline \multirow{2}{*}{$\begin{array}{l}\text { Education status of the } \\
\text { respondent }\end{array}$} & Education and Practices of Malaria Prevention Methods distribution & \\
\cline { 2 - 5 } & Every time & Sometime & Never & Total \\
\hline Illiterate & 123 & 55 & 36 & 214 \\
\hline Only read and write & 8 & 16 & 5 & 29 \\
\hline Grade 1-8 & 4 & 12 & 7 & 23 \\
\hline Grade 9-12 & 3 & 0 & 1 & 4 \\
\hline Above Grade 12 & 1 & 0 & 0 & 1 \\
\hline Total & 139 & 83 & 49 & 271 \\
\hline
\end{tabular}

Table 12: Relation of Respondents' occupational status with their practices level toward of malaria prevention methods, at Gode lalo kebele, $2018(n=271)$.

\begin{tabular}{|l|l|l|l|l|}
\hline $\begin{array}{l}\text { Occupational status of the } \\
\text { respondents }\end{array}$ & \multicolumn{3}{l|}{ Occupational Status with related to practices of malaria prevention methods } \\
\hline & Every time & Sometime & Never & Total \\
\hline Governmental Employer & 1 & 0 & 0 & 1 \\
\hline Farmer & 107 & 36 & 33 & 176 \\
\hline Merchant & 8 & 5 & 3 & 16 \\
\hline House wife & 23 & 42 & 13 & 78 \\
\hline Total & 139 & 83 & 49 & 271 \\
\hline
\end{tabular}


Table 13: Respondents reasons for not using malaria prevention methods at Gode lalo Keble, $2018(n=271)$.

\section{Reasons for not using Malaria Prevention Methods}

\begin{tabular}{|l|l|l|}
\hline & Frequency & Percent \\
\hline It is expensive & 30 & 11.1 \\
\hline Dot accessible in our local & 81 & $29 . .9$ \\
\hline Don't wnow where it is available & 13 & 4.7 \\
\hline Methods beyond individual/needs community effort & 5 & 2 \\
\hline Every time in use & 3 & 1 \\
\hline Total & 139 & 51.3 \\
\hline
\end{tabular}

of the respondents don't want to use it, for $1 \%$ of the respondents the methods are beyond individual/needs community effort/and beyond all this Reasons $51.3 \%$ of the respondents every time used malaria prevention methods (Table 13).

\section{Discussion}

In this study the knowledge and awareness of the respondents, $83 \%$ have good knowledge while $10 \%$ had satisfactory knowledge and $7 \%$ of the respondents had poor knowledge of Malaria protection methods. All the respondents; have heard about malaria, $76.8 \%$ of the respondents are aware of its mode of transmission from person to person, $98.5 \%$ of the respondents are aware of its preventability while $23.2 \%$ of the respondents did not know the mode of transmission for malaria and $1.5 \%$ of the respondents respond that malaria is not a Preventable disease. This is almost similar with the study conducted; in Cameroon at the mount fako region in 2011, in Ethiopia East hareghe zone Afdem area in 2015, in Ethiopia Shashemene Woreda, Oromia Regional State in 2011, and in Uganda in 2013.

The Attitude towards Malaria Prevention Methods of large majority of the respondents $(87.8 \%)$ was positive, while $12.2 \%$ of the respondents had negative attitude towards Malaria protection methods. The results of this study are almost similar with the study conducted; in Cameroon at the mount fako region in 2011, in Ethiopia Shashemene Woreda, Oromia Regional State in 2011, and in Uganda in 2013.

The practice of Malaria Prevention Methods of Large majority of the respondents (51.3\%) practice of Malaria Prevention methods Every time while $30.6 \%$ of the respondents sometime practice Malaria prevention methods and $18.1 \%$ of the respondents had never practiced Malaria prevention methods. The results of this study are almost similar with the study conducted; in Cameroon at the mount fako region in 2011, in Ethiopia Shashemene Woreda, Oromia Regional State in 2011, and in Uganda in 2013.

The association between respondents Gender and their practice of malaria prevention methods are presented among respondents with Gender and Practices status who are male 71 (26.2\%) and Female 68 (25\%), male 65 (24\%) and Female 18 (6.6\%) and male 42 $(15.5 \%)$ and Female $7(2.6 \%)$ respectively practice malaria prevention methods every time, sometime and never. Similarly significant association was not found in all studies conducted; in Southern Ghana in 2015, in Cameroon at the mount fako region in 2011, in Ethiopia Shashemene Woreda, Oromia Regional State in 2011, and in Uganda in 2013.

The association between respondents Age and their practice of malaria prevention methods are presented among respondents with age in years status who are $18-20$ years, $20-30$ years, $31-40$ years, $41-50$ years and above 50 years 9 (3.3\%), 83 (30.6\%), 29 (10.7\%), 7 (2.6\%), 11 (4\%) respectively practice malaria prevention methods every time, respondents with age in years status who are 18-20 years, 20-30 years, 31-40 years, $41-50$ years and above 50 years $4(1.5 \%), 35$ (12.9\%), $29(10.7 \%), 7(2.6 \%), 8(3 \%)$ respectively practice malaria prevention methods Sometime and among respondents with age in years status who are 18-20 years, 20-30 years, 31-40 years, $41-50$ years and above 50 years $3(1.1 \%), 18(6.6 \%), 16(5.9 \%), 6(2.2 \%), 6(2.2 \%)$ respectively practice malaria prevention methods never Similarly significant association was found in all Studies conducted; in Southern Ghana in 2015 and in Uganda in 2013.

The association between respondents Education and their practice of malaria prevention methods are presented among respondents with Education status who are illiterates, only reading and writing, grade $1-8$, grade 9-12 and above grade 12, 123 (45.4\%), 8 (3\%), 4 $(1.5 \%), 3(1.1 \%), 1(0.4 \%)$ respectively practice malaria prevention methods every time, respondents with Education status who are illiterates, only reading and writing, grade 1-8, grade 9-12 and above grade 12,55 (20.3\%), $16(5.9 \%), 12(4.4 \%), 0(0 \%), 0(0 \%)$ respectively practice malaria prevention methods sometime and among respondents with Education status who are illiterates, only reading and writing, grade $1-8$, grade 9-12 and above grade 12, 36 (13.3\%), 5 (1.9\%), 7 (2.6\%), $1(0.4 \%), 0(0 \%)$ respectively practice malaria prevention methods Never. Similarly significant association was not found in studies conducted; in Cameroon at the mount fako region in 2011, in Ethiopia Shashemene Woreda, 
Oromia Regional State in 2011, and in Uganda in 2013. Differently significant association was found in studies conducted; in Southern Ghana in 2015, and in Ethiopia Shashemene Woreda, Oromia Regional State in 2011.

The association between respondents Occupational Status and their practice of malaria Prevention methods are presented among respondents who are Governmental Employer, Farmer, merchant, Daily laborers, House wife, Jobless and others, 1 (0.4\%), 107 (39.5\%), 8 (3\%), $0(0 \%), 23(8.5 \%), 0(0 \%), 0(0 \%)$ every time, $0(0 \%)$, $36(13.3 \%), 5(1.9 \%), 0(0 \%), 42(15.5 \%), 0(0 \%), 0(0 \%)$ some time and $0(0 \%), 33(12.2 \%), 3(1.1 \%), 0(0 \%), 13$ $(4.8 \%), 0(0 \%), 0(0 \%)$ Never respectively practice malaria prevention methods. Similarly significant association was not found in studies conducted; in Cameroon at the mount fako region in 2011.

The association between respondents Average Monthly Income and their practice of malaria prevention methods are presented. According to respondents with monthly income of < 600 birr, 600-1200 birr, 1201-1500 birr and > 1500 birr is 3 (1.1\%), 131 (48.3\%), 5 (1.9\%) and $0(0 \%)$ every time, $20(7.4 \%), 42(15.5 \%), 17(6.3 \%)$ and $4(1.5 \%)$ sometimes and 32 (11.8\%), 14 (5.2\%), 3 $(1 \%)$ and $0(0 \%)$ never respondents respectively practice malaria prevention methods. Similarly significant association was not found in studies conducted; in Cameroon at the mount fako region in 2011. The Reasons for not using Malaria Prevention Methods for Large majority of the respondents (29.9\%) was lack of accessibility, for $11.1 \%$ of the respondents the methods were expensive, $4.7 \%$ of the respondents didn't know where the methods were available, $2 \%$ don't want to use it, for $1 \%$ of the respondents the Methods are beyond individual/needs community effort/and beyond all this Reasons $51.3 \%$ of the respondents Every time used Malaria prevention methods. Similarly; According to study conducted; in Cameroon at the mount fako region in 2011, Reasons for not Using Malaria Prevention Methods are not cost effective, the belief that ITN had multiple Consequences of adverse toxic effect, and the fear of illnesses such as cough and irritation, Seemed to be common among subjects. Other factors or barriers that reduced the widespread. Adherence to ITNs include: high cost of nets, inconveniences due to hot weather and some Cultural beliefs, and according to the study conducted in rural areas of mundri east county, Southern Sudan in 2011, respondents' lack of money, shortage of time to consistently spray Their homes, lack of equipment to spray the home, inability replace if any broken gauze screens If it should break, lack of equipment to spray mosquitoes in village and did lack of mosquito Repellents at home for repelling mosquitoes have hindered use of MPM.

\section{Conclusion}

The findings of this study shows, study community have good knowledge on both malaria and its control in- terventions and have positive attitude towards malaria prevention methods. Despite study communities' good knowledge and positive attitude most of them practiced Malaria prevention methods occasionally and few others never practiced them. Study results also indicated that there was association between some demographic characteristics and communities practice of malaria prevention methods.

\section{Recommendations}

To enhance the community members to practice malaria prevention methods all the time it is recommended that Health sector officials should; increase accessibility, provide them at affordable price, increase community awareness about their availability, coordinate community effort so that malaria prevention methods which were unaffordable at individual level could be affordable at community level.

\section{Consent for Publication}

Not applicable.

\section{Availability of Data and Materials}

This is a research article.

\section{Competing Interests}

We declare that we have no competing interests.

\section{Funding}

None.

\section{Acknowledgment}

We would like to extend appreciations to individuals who involved in data collection and also would like to thank to members of Godelalo kebele (010), Anchar Woreda, west Haraarge Zone, Oromia, Regional state, Ethiopia, for responding to research survey questionnaire.

\section{Authors' Contribution}

RM, MT and ML conceived the study, participated in the design, data analysis and interpretation of the result. RM involved in data acquisition, writing the draft manuscript as well as making all the changes as suggested by the coauthors. MT and ML critically reviewed the manuscript. All authors read and approved the manuscript.

\section{Operational Definition}

$\checkmark$ An overall knowledge score was calculated by adding up the scores for each respondent across all fourteen questions.

$\checkmark$ Those whose score are equal to mean score (75\%) or above were taken as having good knowledge.

$\checkmark$ Respondents who answer $50 \%$ - $75 \%$ of knowledge testing the questions correctly was considered as having Satisfactory knowledge. 
while those with score of less than $50 \%$ were considered as having poor knowledge about malaria.

$\checkmark$ woreda, are the third-level administrative divisions of Ethiopia.

$\checkmark$ A kebele: is the smallest administrative unit of Ethiopia, similar to a ward, a neighbourhood or a localized and delimited group of people (Annex 1).

\section{References}

1. WHO (2011) Knowledge, Attitudes and Practices on Malaria Prevention and Control in Girmberg and mehlotra.

2. Bang AT, Bang RA, Reddy HM (2005) Home-based neonatal care: Summary and applications of the field trial in rural Gadchiroli, India (1993 to 2003). J Perinatol 25: 108122.

3. (2016) Ethiopia National Malaria Indicator Survey 2015.

4. WHO (2010) WHO Malaria Report 2010.
5. FMOH (2014) National Strategic Plan for Malaria Prevention, Control and Elimination in Ethiopia: 2014-2020.

6. WHO (2012) World Malaria Report 2012.

7. (2013) World Malaria Report 2013.

8. FdroEmo (2010) Disease prevention and control department: Malaria control profile.

9. Wakgari Deressa, Ahmed Ali, Fikre Enquoselassie (2003) Knowledge, attitude and practice about malaria, the mosquito and ant malarial drugs in a rural community. Ethiop J Health Dev 17: 99-104.

10. Admasu A (2005) A Study on Knowledge, Attitude and Practice about Malaria Awareness and Bed Net Use. Gondar College of medicine and health science, from model of malaria. 13-4.

11. (2012) Ethiopia National Malaria Indicator Survey Technical summary 2011. 


\section{Annex-1: Questionnaire}

Questionnaire on knowledge, attitude and practice on malaria prevention Gode lalo Kebele, anchar Woreda, West Hararge, Oromia, Ethiopia.

Introduction

1. The respondents of these questionnaires are the head of the house hold, their spouses or member of the household.

2. Respondents are expected to answer these questions by themselves based on their Socio-demographic background, knowledge, attitude and a practice towards malaria prevention.

General information

House No given by Interviewee:

Address Keble:

1. Demographic characteristics

1.1. Age in years

1.2. Gender: A. Male B. Female

1.3. Marital status: A. Single B. Married C. Divorced D. Widowed

1.4. Family size:

1.5. Religion: A. Orthodox B. Muslim C. Protestant D. Others

1.6. Ethnicity: A. Oromo B. Amhara C. Gurage D. Argoba E. Others

1.7. Educational status.

A. Illiterate B. Only read and write C. Grade 1-8 D. Grade $9-12$

E. $12+$

1.8. Occupational status

A. Government employee B. Farmer C. Merchant D. Daily laborer

E. House wife F. Jobless G. Other specify

1.9. Average Monthly Income

A. $<600$ Birr B. $600-1200$ Birr C. 1201-1500 birr D. >1500 birr

2. Knowledge about Malaria prevention

2.1. Have you ever heard about malaria?
A. yes
B. No.

2.2. Malaria disease has a problem in the area?
A. yes
B. No.

2.3. If your response is yes to question no 2.2. Where did you first get information?
A. Mass media
B. Health workers
C. Religious Leaders
D. Family, Friends, neighbors and colleagues
E. Others (please explain)

2.4. What are the signs and symptoms of malaria?
A. Fever
D. Loss of appetite
B. Chills and shivering
E. Feeling of thirst
C. Headache
F. Back or joint pain
G. Vomiting
H. Weakness
I. Dark red or Black urine
J. Yellowish discoloration of the eye 


\section{K. Other specify}

2.5. Do you know the mode of transmission for malaria?
A. Mosquito bite.
B. Patient contact.
C. Hot environment
D. Mother to child transmission during pregnant.
D. Malnutrition
E. Fly
F. malaria infected blood to give another parson
G. Other specify
H. I don't specify

2.6. Can malaria be transmitted from person to person? (if no Answer skip to question no 2.8)
A. Yes
B. No

2.7. If yes to question 2.6, how is malaria transmitted?
A. Mosquito bites
B. Contact With sick
C. Contact with fomented
D. Poor personal and environmental hygiene
E. Exposed to sun? Warm weather
F. Exposed to rain

2.8. Where do mosquitoes mostly breed??
A. Marshy area
B. stagnant water
C. Back yard plantation D.
Discarded materials
E. Human and animal waste F. Other (specify)

2.9. When do mosquitoes mostly bite? A. days B. Night C. I don't know

2.10. Is malaria preventable disease? (If no Answer skips to question no 2.13) A. Yes B. No

2.11. If yes to question no 2.10 , what preventive method do you know?
A. Anti-mosquito spray in the house.
B. Sleep in a mosquito net.
C. Repair mosquito net holes.
D. Application of insect replant to expose skin.
E. Drainage of stagnant water.
F. Clean bushes around the house.
G. Smoking local woods/Animal dung/
$H$. Visit the health center when fail sick
I. Wearing cloths which cover all the body during night.
J. Others
K. I don't know any method

2.12. If question no 2.11 selected why you choice preferred method?

A. Easily available B. More effective C. Low cost D. Others----------

2.13. Reasons for not using any protective methods, if any?

A. Not affordable B. Not available C. Not aware about its use

2.14. what do you do if you or your family member gets sick from malaria?

A. Take him to Hospital 

B. Take him to Health center
C. Take him to Health clinic/post
D. Take him to Private clinics
E. Take him to Private pharmacies/drug store
F. Purchase drugs from shops
G. Take him to Traditional healer
H. Use the left over drugs
I. Use traditional remedies at home
J. Others-
K. I do not use any method

\section{Attitude towards Malaria prevention}

3.1. I think that Malaria is a serious and life-threatening disease.
A. Agree
B. Strongly agrees
C. Disagree
D. Strongly disagree

3.2.I thinks malaria is can transmitted from person to person with similar communicable disease ?
A. Agree
B. Strongly agree
C. Disagree D. Strongly disagree

3.3. I think the best way to prevent myself from getting Malaria is to avoid getting mosquito bites.
A. Agree
B. Strongly agree
C. Disagree D. Strongly disagree

3.4. I believe sleeping under a mosquito net during the night is one way to prevent myself getting Malaria
A. Agree
B. Strongly agree
C. Disagree D. Strongly disagree

3.5. I thinks malaria is greater risk for child, pregnant women and malnutrition person?
A. Agree
B. Strongly agree
C. Disagree D. Strongly disagree

3.6. I might be at a greater risk of getting Malaria if I work and sleep overnight in the garden or forest
A. Agree
B. Strongly agree
C. Disagree D. Strongly disagree

3.7. I think malaria is a curable disease
A. Agree
B. Strongly agree
C. Disagree D. Strongly disagree

3.8. I think that I should go to the health centre/clinic to have my blood tested as soon as I suspect that I have suffered from Malaria
A. Agree
B. Strongly agree
C. Disagree
D. Strongly disagree

3.9. I might be at a greater risk of getting Malaria if I don't fully cover all my body during night
A. Agree
B. Strongly agree
C. Disagree D. Strongly disagree

3.10. I will seek for advice or treatment when I get Malaria
A. Agree
B. Strongly agree
C. Disagree D. Strongly disagree

4. Practices towards Malaria prevention

4.1. How often do you sleep in a mosquito net?
A. Every time
B. Sometimes
C. Never

4.2. How often do other members of the household sleep in mosquito nets?
A. Every time
B. Sometimes
C. Never

4.3. How often do you check for holes/repair mosquito nets?
A. Every time
B. Sometimes
C. Never 
4.4. How often do you use mosquito repellent coils on your house?
A. Every time
B. Sometimes
C. Never

4.5. How often do you use anti-mosquito spray in your house?
A. Every time B. Sometimes C. Never

4.6. How often do you clean/cut bushes around your house?
A. Every time
B. Sometimes
C. Never

4.7. How often do you clean stagnant water near your house?

A. Every time B. Sometimes C. Never

4.8. How often do you visit the health centre when you fall sick?
A. Every time B. Sometimes C. Never

4.9. How often do you receive visits from the Village Health Team?

A. Every time B. Sometimes C. Never

4.10. How often do you smoke local woods/Animal dung/?

A. Every time B. Sometimes C. Never

4.11. How often do you wear cloths which cover all your body during night?

A. Every time B. Sometimes C. Never

4.12. Among the prevention methods listed above are there methods you never used?
A. Yes B. No

4.13. If yes, to question no 4.12 why you don't use malaria the preventive method?
A. It is expensive
B. No accessible in our local
C. I don't know where it is available
D. I don't want to use it
E. Methods beyond individual/needs community effort/ 